\title{
Asymmetric Glycolated Substitution for Enhanced Permittivity and Ecocompatibility of High-Performance Photovoltaic Electron Acceptor
}

Tengfei Li, Kang Wang, Guilong Cai, Yawen Li, Heng Liu, Yixiao Jia, Zhenzhen Zhang, Xinhui Lu, Ye Yang, * and Yuze Lin*

Cite This: JACS Au 2021, 1, 1733-1742

Read Online

\section{ACCESS |}

W Metrics \& More

回国 Article Recommendations

Supporting Information

ABSTRACT: Traditional organic photovoltaic materials exhibit low dielectric constants $\left(\varepsilon_{\mathrm{r}}\right)$ of 3 to 4 , restricting the further enhancement of power conversion efficiencies (PCEs) of organic solar cells (OSCs). Herein we design and synthesize a fused-ring electron acceptor named Y6-4O through introducing an asymmetric highly polarizable oligo(ethylene glycol) side chain onto the pyrrole unit of Y6. Compared with alkylated Y6 $\left(\varepsilon_{\mathrm{r}}=3.36\right)$, asymmetric glycolated Y6-4O shows a notably higher $\varepsilon_{\mathrm{r}}$ value of 5.13 and better solubility in nonhalogen solvents. Because of the higher $\varepsilon_{\mathrm{r}}$ value, the devices based on as-cast PM6:Y6-4O processed using toluene exhibit a higher charge separation yield, slower bimolecular recombination kinetics, and less voltage loss relative to the control devices based on PM6:Y6. Consequently, a high PCE of 15.2\% is achieved for PM6:Y6-4O-based devices, whereas the PM6:Y6-based

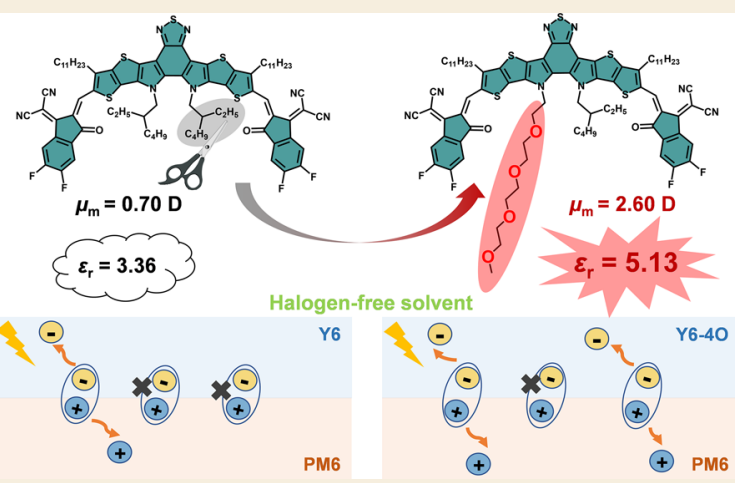
devices show PCEs of only 7.38\%. 15.2\% is the highest PCE for the as-cast nonhalogenated processed OSC devices, and it is also much higher than the values $(<8.5 \%)$ reported for OSCs based on high-permittivity $\left(\varepsilon_{\mathrm{r}}>5\right)$ organic photovoltaic semiconductors. KEYWORDS: organic solar cells, nonfullerene acceptor, high permittivity, ecocompatibility, oligo(ethylene glycol)

\section{INTRODUCTION}

Thanks to their low weight, intrinsic flexibility, semitransparency and large-area processability, organic solar cells (OSCs) have gained broad interest as a promising photovoltaic technology. ${ }^{1-4}$ In particular, in the past 5 years, owing to the rapid development of fused-ring electron acceptors (FREAs), the power conversion efficiencies (PCEs) of OSCs have reached $18 \% .^{5-20}$ However, in comparison with conventional inorganic (e.g., silicon, GaAs) solar cells and hybrid perovskite solar cells, the performance of OSCs still greatly lags behind. ${ }^{21}$ One of the significant limitations for the further PCE enhancement of OSCs is the relatively low dielectric constant $\left(\varepsilon_{\mathrm{r}}\right)$ of traditional organic photovoltaic semiconductors $\left(\varepsilon_{\mathrm{r}}\right.$ of 3 to 4$)$, which limits the exciton dissociation efficiency. ${ }^{22}$ In contrast, the typical inorganic/hybrid semiconductors exhibit higher $\varepsilon_{\mathrm{r}}$ values $(\mathrm{Si}: \sim 12$, GaAs: $\sim 12$, and perovskite: $\sim 18) .^{23-25}$ A high $\varepsilon_{\mathrm{r}}$ can reduce the Coulomb attraction within excitons, facilitating the charge separation at the donor/ acceptor interface with decreased charge recombination possibility, which can boost the device efficiency enhancement. ${ }^{26} \mathrm{~A}$ small exciton binding energy $\left(E_{\mathrm{b}}\right)$ given a value close to thermal energy $k_{\mathrm{B}} \mathrm{T}\left(k_{\mathrm{B}}\right.$ is the Boltzmann constant, $T$ is the absolute temperature) can make it promising for OSCs to acquire an enhanced PCE of $>20 \%{ }^{22}$
In recent years, very limited approaches have been reported to enhance the permittivity of organic semiconductors, including the introduction of polarizable units (e.g., cyano groups, fluorine atoms, and oligo(ethylene glycol) (OEG) side chains) on the molecular skeleton and the addition of highpermittivity materials in the photoactive layer. ${ }^{27}$ However, the other imperfect intrinsic properties of these high-permittivity materials, such as the absorption, energy level, and charge transport, restrain the upper limit of their photovoltaic performance. $^{28-32}$ In addition, most studies acquired high permittivity but brought some negative effects on the crystallinity and compatibility in active layer, which play significant roles in the device optimization. ${ }^{26,33}$ Therefore, it is full of significance and challenge to rationally design highdielectric-constant organic semiconductors holding excellent photovoltaic performance.

Received: July 9, 2021

Published: August 18, 2021 


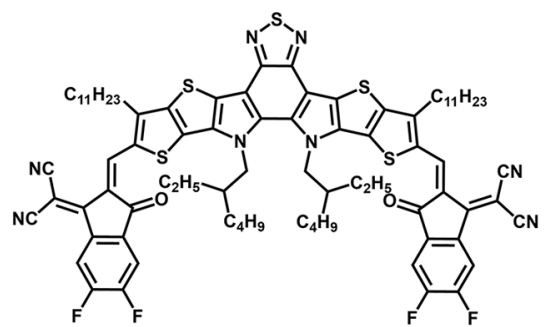

Y6
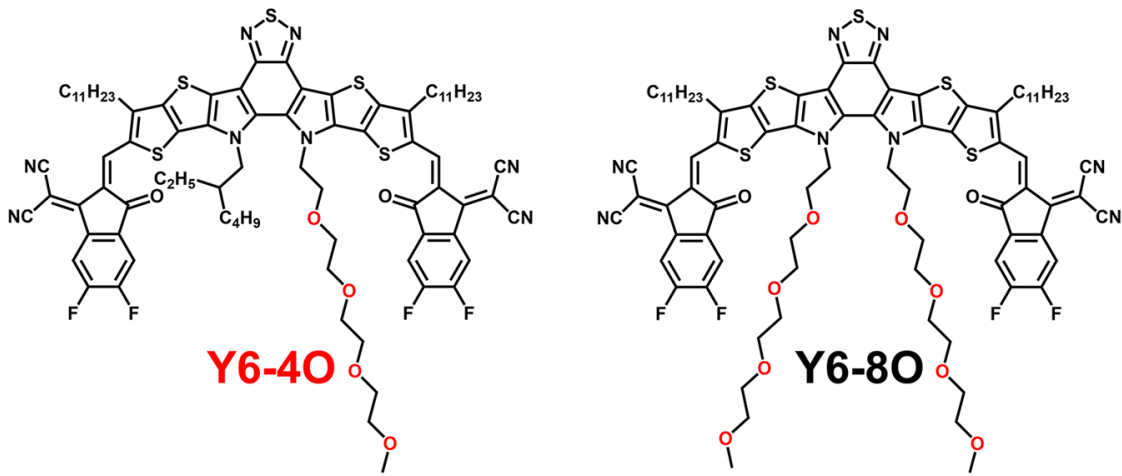

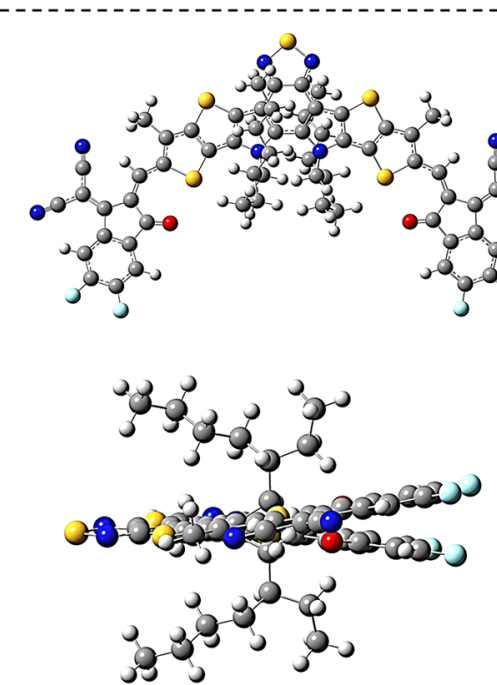

$\mu_{\mathrm{m}}=0.7040 \mathrm{D}$
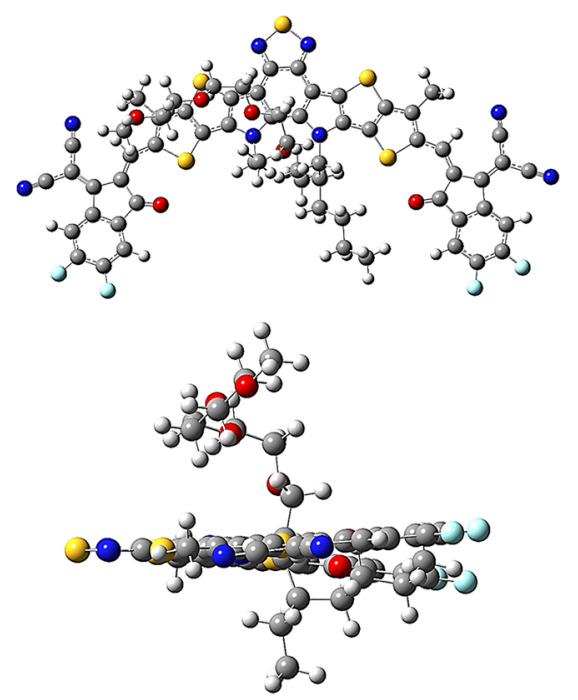

$\mu_{\mathrm{m}}=2.5985 \mathrm{D}$
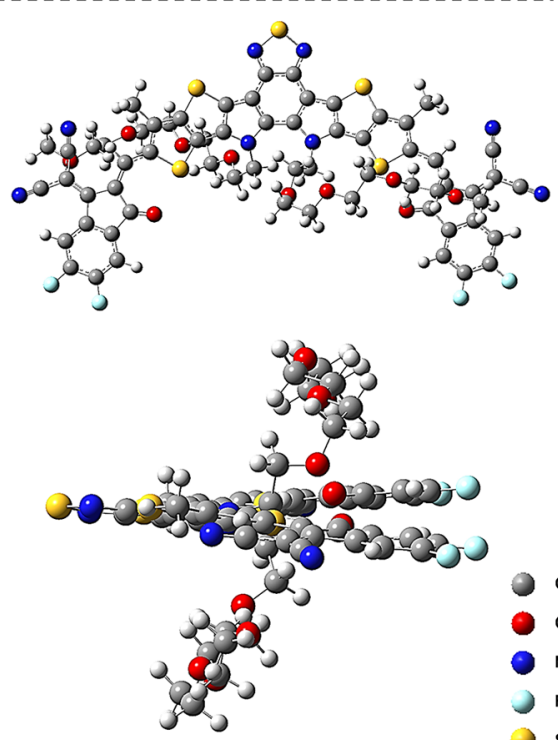

$\mu_{\mathrm{m}}=1.4742 \mathrm{D}$

Figure 1. Chemical structures, dipole moments, and optimal geometries (alkyl groups attaching to thiophene are simplified to methyl) calculated by the Gaussian 09 program at the B3LYP/6-31G* level of Y6, Y6-4O, and Y6-8O.

Here we proposed a rational molecular design strategy named "asymmetric glycolated substitution" for the enhanced permittivity and ecocompatibility of high-performance photovoltaic electron acceptors. We designed and synthesized the FREA Y6-4O via introducing an asymmetric OEG side chain instead of one alkyl side chain on the pyrrole unit of Y6. ${ }^{13}$ Compared with Y6 $\left(\varepsilon_{\mathrm{r}}=3.30 \pm 0.05\right)$, Y6-4O exhibited a higher dielectric constant of $4.77 \pm 0.27$, with a highest value of 5.13, leading to enhanced exciton dissociation and decreased charge recombination in OSC devices. Meanwhile, the introduction of a hydrophilic polarizable glycolated side chain can obviously increase the solubility of $\mathrm{Y} 6-4 \mathrm{O}$ in nonhalogen solvents, which benefits the fabrication of greensolvent-processed OSCs and reduces the harm to human health and the environment. ${ }^{34}$ When blended with polymer donor PM6, the as-cast devices based on glycolated Y6-4O processed using toluene showed a high PCE of 15.2\%, notably better than that of the control devices based on the alkylated Y6 acceptor (7.38\%). 15.2\% is the highest PCE for the as-cast nonhalogenated processed OSC devices and the record PCE for OSCs based on high-permittivity $\left(\varepsilon_{\mathrm{r}}>5\right)$ organic semiconductors.

\section{RESULTS AND DISCUSSION}

\section{Dipole Moment}

The dielectric constant of a material can be described by the Debye equation $^{35}$

$$
\frac{\varepsilon_{\mathrm{r}}-1}{\varepsilon_{\mathrm{r}}+2}=\frac{4 \pi}{3} N\left(\alpha_{\mathrm{e}}+\alpha_{\mathrm{d}}+\frac{\mu_{\mathrm{m}}^{2}}{3 k_{\mathrm{B}} T}\right)
$$

where $N$ is the number density of dipoles, $\alpha_{\mathrm{e}}$ is the electronic polarization, $\alpha_{\mathrm{d}}$ is the distortion polarization, and $\mu_{\mathrm{m}}$ is the dipole moment. According to the Debye equation and previous work, the enhancement of the dipole moment of the molecule generally leads to a higher dielectric constant. ${ }^{36,37}$ Compared with symmetric molecular structures, asymmetric structures usually result in a longer distance between the centers of positive and negative charges, which benefits the enhancement of dipole moments. The density functional theory calculation was used to figure out how the asymmetric introduction of a polarizable side chain affects the $\mu_{\mathrm{m}}$ value of photovoltaic materials by taking $\mathrm{Y} 6$ and the IDIC $^{38}$ molecular skeleton as examples. As a result, the dipole moment of Y6-4O with one OEG side chain was $2.60 \mathrm{D}$, which was indeed higher than those of Y6 (0.70 D) without an OEG side chain and Y6-8O with two OEG side chains $(1.47 \mathrm{D})$ (Figure 1$)$. The same variation change in dipole moment was also seen in the IDIC 
(a)

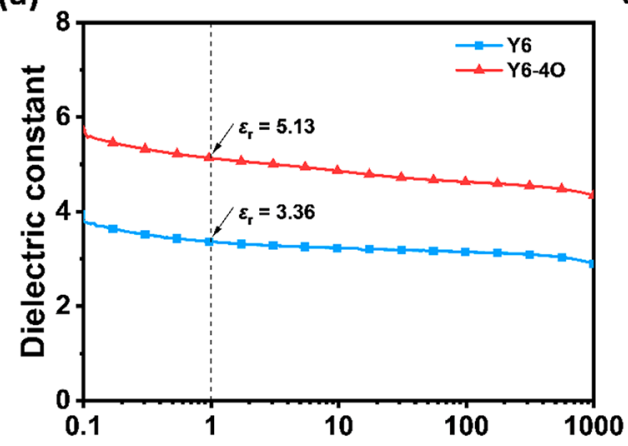

(c)

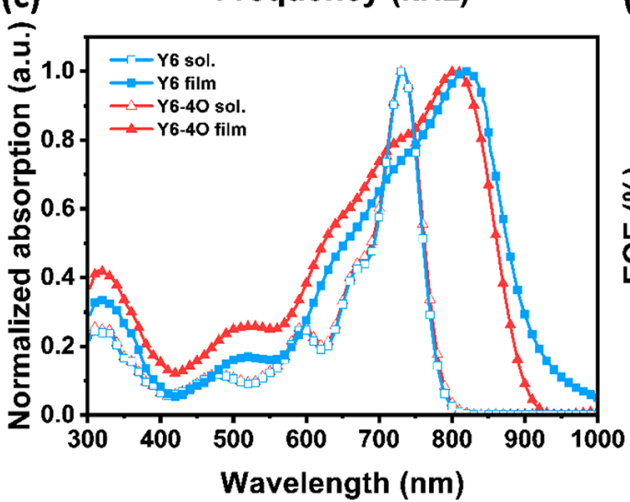

(b)

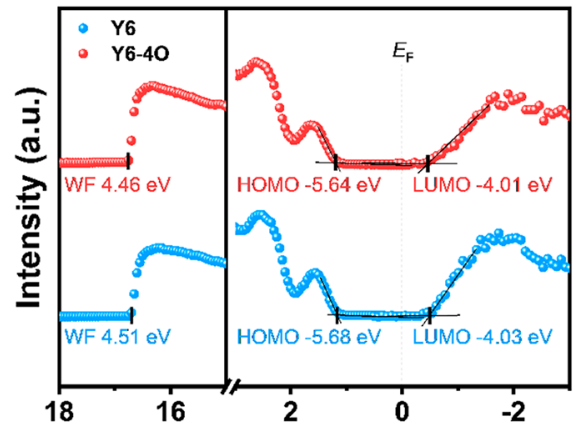

(d)

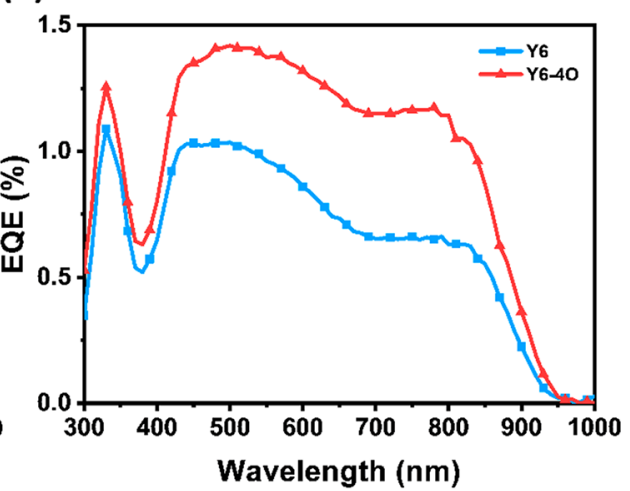

Figure 2. (a) Dielectric constant versus frequency, (b) UPS and LEIPS spectra with respect to the Fermi energy level $\left(E_{\mathrm{F}}\right)$ at $0 \mathrm{eV}$ (work function (WF) values are labeled), (c) absorption spectra, and (d) EQE spectra of single-component devices of Y6 and Y6-4O.

skeleton before and after the asymmetric (IDIC-8O) and symmetric (IDIC-16O) replacement of the alkyl side chain by a polarizable side chain (Figure S1), which supports the universality of the asymmetric substituent enhancing molecular dipole moments.

\section{Synthesis of Y6-40}

Y6-4O with a higher calculated $\mu_{\mathrm{m}}$, which was expected to behave with high permittivity, was synthesized to construct photovoltaic devices. The detailed synthetic route for Y6-4O is shown in Scheme S1. The fused-ring unit with asymmetric side chains (compound 6) was synthesized with dithienothiophen$[3,2-b]$-pyrrolobenzothiadiazole via two-step nucleophilic substitution reactions with 13-iodo-2,5,8,11-tetraoxatridecane and 3-(bromomethyl)heptane, respectively. It is worth noting that during the second step of the substitution reaction, to improve the reactivity, $\mathrm{CsCO}_{3}$ with a stronger nucleophilic ability was used to replace $\mathrm{KOH}$ used in the first step of the reaction. Then, formylated compound 7 was obtained via a Vilsmeier-Haack reaction using anhydous dimethylformamide and $\mathrm{POCl}_{3}$. Finally, the target molecule $\mathrm{Y} 6-4 \mathrm{O}$ was afforded by a Knoevenagel condensation between compound 7 and 3-(1,1dicyanomethylene)-5,6-difluoro-1-indanone. ${ }^{39}$ All of the new compounds were fully characterized by spectroscopic methods. (See the Supporting Information.)

\section{Dielectric Constant and Exciton Binding Energy}

We studied the dielectric constants of $\mathrm{Y} 6-4 \mathrm{O}$ and $\mathrm{Y} 6$ through the parallel-plate capacitance measurement with impedance spectroscopy. The device structure was indium tin oxide (ITO)/poly (3,4-ethylenedioxythiophene): poly(styrenesulfonate) (PEDOT:PSS)/test film/Ca/Al. The $\varepsilon_{\mathrm{r}}$ value can be obtained from the equation

$$
C=\varepsilon_{0} \varepsilon_{\mathrm{r}} A / d
$$

where $C$ is the measured capacitance, $\varepsilon_{0}$ is the permittivity of free space, $A$ is the device area, and $d$ is the thickness of the test film. The dielectric constants are plotted in Figure $2 \mathrm{a}$ as a function of the frequency. In the test frequency range (0.1$1000 \mathrm{kHz}$ ), Y6 showed a common $\varepsilon_{\mathrm{r}}$ of 2.8 to 3.8 , whereas Y6$4 \mathrm{O}$ exhibited a notably higher $\varepsilon_{\mathrm{r}}$ of 4.4 to 5.7. At a frequency of $1 \mathrm{kHz}$ (a common frequency for the comparison of $\varepsilon_{\mathrm{r}}$ values $\left.{ }^{26}\right)$, Y6 exhibited a $\varepsilon_{\mathrm{r}}$ of $3.30 \pm 0.05$ with a maximum of 3.36, obviously lower than that of Y6-4O (4.77 \pm 0.27 with a maximum of 5.13). The enhancement of the dielectric property originates from the molecular asymmetry and the flexibility of the OEG side chain, which is beneficial for the reorientation of the dipole moment. ${ }^{40} E_{\mathrm{b}}$ can be approximately regarded as the Coulomb attraction between the hole and the electron in the exciton, which is inversely proportional to the dielectric constant. ${ }^{41}$ Therefore, we can reasonably deduce that the $E_{\mathrm{b}}$ of $Y 6-4 O$ could be smaller than that of Y6.

The $E_{\mathrm{b}}$ can be obtained from the difference between the transport gap $\left(E_{\mathrm{g}}{ }^{\mathrm{t}}\right)$ and the optical band gap $\left(E_{\mathrm{g}}{ }^{\mathrm{opt}}\right) . E_{\mathrm{g}}{ }^{\mathrm{t}}$ is defined as the difference between the lowest unoccupied molecular orbital (LUMO) and the highest occupied molecular orbital (HOMO) energy. $E_{\mathrm{g}}{ }^{\text {opt }}$ is defined as the lowest optical transition (the energy between the ground state and the lowest excited state) that results in the formation of an exciton. ${ }^{42}$ From the measurement result of the ultraviolet photoelectron spectroscopy (UPS) and low-energy inverse photoemission spectroscopy (LEIPS) (Figure 2b), Y6-4O exhibited slightly higher energy levels (LUMO/HOMO: $-4.01 /-5.64 \mathrm{eV}$ ) than those of Y6 (LUMO/HOMO: $-4.03 /-5.68 \mathrm{eV}$ ), which indicates that the introduction of an asymmetric OEG side chain has a negligible impact on the 
(a)
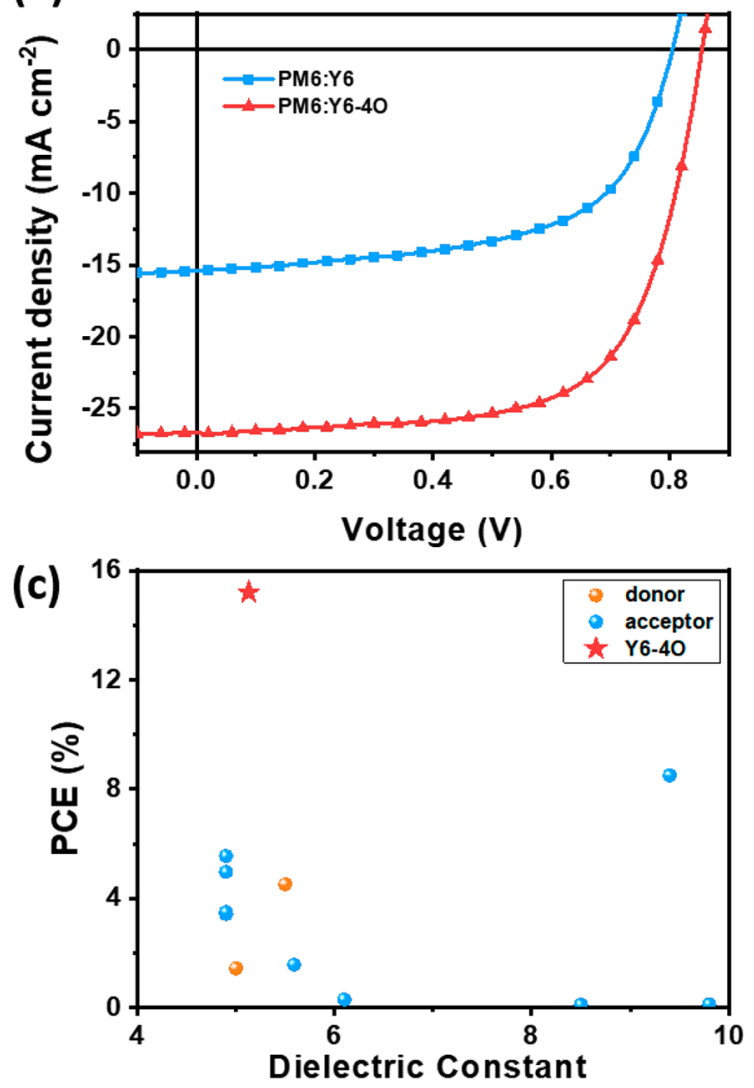

(b)
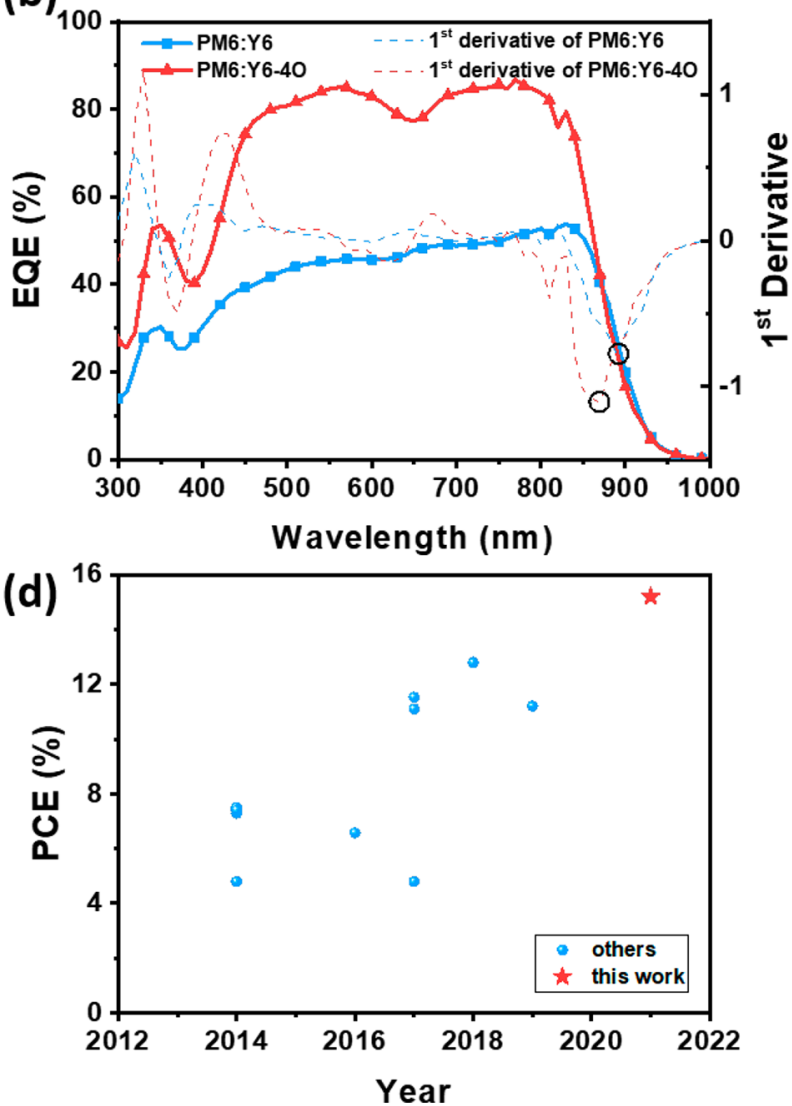

Figure 3. (a) $J-V$ curves and (b) EQE spectra with first derivative curves of the devices based on as-cast PM6:Y6 and PM6:Y6-4O processed using toluene. Summarized PCEs for (c) the recently reported OSCs based on high-dielectric-constant organic semiconductors and (d) the recently reported as-cast OSCs processed using nonhalogen solvents.

Table 1. Photovoltaic Performances of As-Cast OSCs Processed Using Toluene

$\begin{array}{lcccc}\text { active layer } & V_{\mathrm{OC}}(\mathrm{V})^{a} & J_{\mathrm{SC}}\left(\mathrm{mA} \mathrm{cm}^{-2}\right)^{a} & \text { FF }(\%)^{a} & \text { PCE }(\%)^{a} \\ \text { PM6:Y6 } & 0.804 \pm 0.002(0.804) & 15.3 \pm 0.4(15.4) & 58.2 \pm 0.9(59.6) & 7.17 \pm 0.16(7.38) \\ \text { PM6:Y6-4O } & 0.850 \pm 0.006(0.854) & 26.1 \pm 0.3(26.7) & 67.2 \pm 0.6(66.4) & 14.9 \pm 0.1(15.2)\end{array}$

${ }^{a}$ Average values with standard deviation were obtained from 10 devices, and the values in brackets are the parameters of the best device.

energy levels. ${ }^{29} E_{\mathrm{g}}{ }^{\mathrm{t}}$ values were calculated to be $1.65 \mathrm{eV}$ for $\mathrm{Y} 6$ and $1.63 \mathrm{eV}$ for $\mathrm{Y} 6-4 \mathrm{O}$, respectively. In the meantime, the $\mathrm{CHCl}_{3}$-cast film of Y6-4O exhibited slightly blue-shifted absorption with an $E_{\mathrm{g}}^{\text {opt }}$ of $1.39 \mathrm{eV}$, relative to $\mathrm{Y} 6$ with an $E_{\mathrm{g}}{ }^{\text {opt }}$ of $1.35 \mathrm{eV}$, calculated from the absorption onset (Figure $2 \mathrm{c})$. As a result, the $E_{\mathrm{b}}$ of $\mathrm{Y} 6-4 \mathrm{O}(0.24 \mathrm{eV})$ was smaller than that of Y6 $(0.30 \mathrm{eV})$, which is consistent with the result deduced from $\varepsilon_{\mathrm{r}}$.

\section{Photovoltaic Performance}

To study the effect of asymmetric polarizable OEG introduction on exciton dissociation, we fabricated singlecomponent devices with a structure of ITO/PEDOT:PSS/ active layer/PDINN ${ }^{43} / \mathrm{Ag}$. Y6-based devices showed a $J_{\mathrm{SC}}$ of $0.316 \mathrm{~mA} \mathrm{~cm}^{-2}$ (Table S1). In contrast, the devices based on Y6-4O exhibited an enhanced $J_{\mathrm{SC}}$ of $0.476 \mathrm{~mA} \mathrm{~cm}{ }^{-2}$, which was supported by the improvement in the external quantum efficiency (EQE) response (Figure 2d). For single-component devices, the efficiency of the photocurrent generation is mainly related to the efficiency of the photon absorption $\left(\eta_{\mathrm{A}}\right)$, exciton dissociation $\left(\eta_{\mathrm{ED}}\right)$, charge transport $\left(\eta_{\mathrm{T}}\right)$, and charge collection $\left(\eta_{\mathrm{CC}}\right){ }^{44}$ Each process was analyzed to figure out which contributed to the increase in $J_{\mathrm{SC}}$. The maximum molar extinction coefficient of Y6-4O $\left(1.7 \times 10^{5} \mathrm{M}^{-1} \mathrm{~cm}^{-1}\right)$ was a little lower than that of Y6 $\left(1.9 \times 10^{5} \mathrm{M}^{-1} \mathrm{~cm}^{-1}\right)$, and the $E_{\mathrm{g}}{ }^{\mathrm{opt}}$ of $\mathrm{Y} 6-4 \mathrm{O}$ was larger than that of $\mathrm{Y} 6$, which implies that the $\eta_{\mathrm{A}}$ of the Y6-4O-based device is lower than that of the Y6-based device. According to the space-charge-limited current (SCLC) ${ }^{45}$ method, Y6-4O had a lower electron mobility $\left(\mu_{\mathrm{e}}\right)$ value of $0.92 \times 10^{-4} \mathrm{~cm}^{2} \mathrm{~V}^{-1} \mathrm{~s}^{-1}$ than that of Y6 $\left(\mu_{\mathrm{e}}=2.0\right.$ $\left.\times 10^{-4} \mathrm{~cm}^{2} \mathrm{~V}^{-1} \mathrm{~s}^{-1}\right)$, suggesting that the $\eta_{\mathrm{T}}$ of the device based on $\mathrm{Y} 6-4 \mathrm{O}$ is lower than that of the Y6-based device (Figure S2). Meanwhile, because of the same electrodes, $\eta_{\mathrm{CC}}$ was considered to be similar for the devices. Hence, the increase in $J_{\text {SC }}$ for Y6-4O-based devices was likely to be attributed to the better exciton dissociation caused by its higher dielectric constant. $^{44}$

To study the photovoltaic performance of $\mathrm{Y} 6-4 \mathrm{O}$ as an electron acceptor, we blended the commercial polymer $\mathrm{PM} 6^{46}$ (Figure S3) as the donor material for its complementary absorption spectra and matched energy levels (Figure S4). The device structure of ITO/PEDOT:PSS/active layer/PDINN/ Ag was employed. Taking the excellent solubility of glycolated Y6-4O into account, we processed the active layer with several 

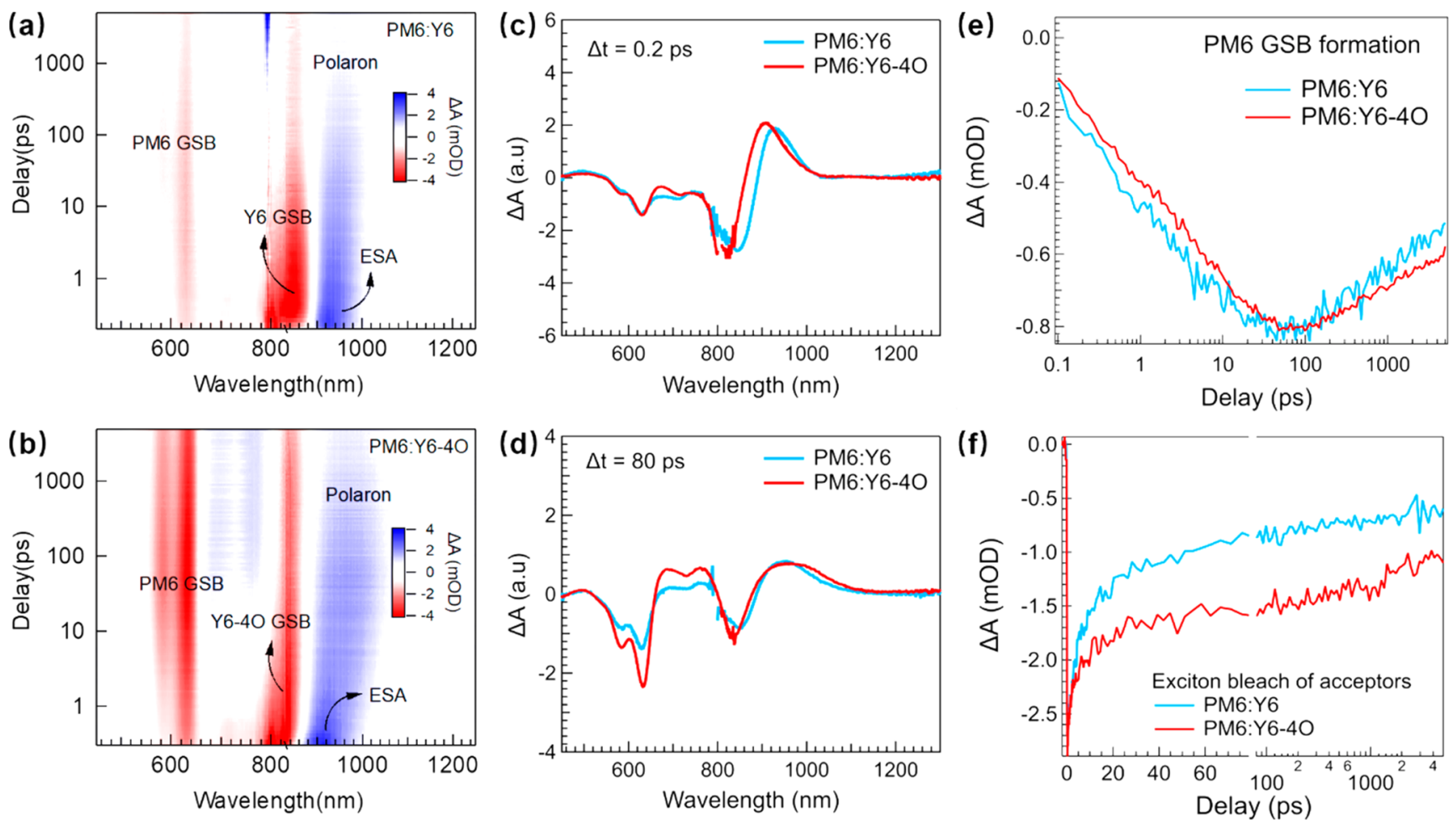

Figure 4. (a,b) Broadband TA data of PM6:Y6 and PM6:Y6-4O blend films. (c,d) TA spectra of PM6:Y6 and PM6:Y6-4O blend films at delay times of 0.2 and 80 ps. (e) TA kinetics of PM6 GSB in PM6:Y6 and PM6:Y6-4O blend films. (f) TA kinetics of the exciton bleach of acceptors in PM6:Y6 and PM6:Y6-4O blend films.

nonhalogen solvents (toluene (TL), xylene, and tetrahydrofuran) without any other treatment (Table S2), which benefitted the reduction of pollution to the environment. Consequently, the toluene-processed PM6:Y6-4O-based devices showed the best device performance: an open-circuit voltage $\left(V_{\mathrm{OC}}\right)$ of $0.854 \mathrm{~V}, J_{\mathrm{SC}}$ of $26.7 \mathrm{~mA} \mathrm{~cm}{ }^{-2}$, fill factor $(\mathrm{FF})$ of $66.4 \%$, and PCE of $15.2 \%$ (Figure 3a, Table 1). By contrast, the control devices based on PM6:Y6 showed a lower $V_{\mathrm{OC}}$ of $0.804 \mathrm{~V}, J_{\mathrm{SC}}$ of $15.4 \mathrm{~mA} \mathrm{~cm}{ }^{-2}$, FF of $59.6 \%$, and PCE of $7.38 \%$. The $J_{\text {SC }}$ values calculated by integrating the $\mathrm{EQE}$ spectra with the AM $1.5 \mathrm{G}$ reference spectrum were close to those obtained from $J-$ $V$ measurements with a mismatch of $<5 \%$ (Figure $3 \mathrm{~b}$ ). In comparison with the PM6:Y6-based devices with a low EQE response of about 40 50\%, the PM6:Y6-4O system exhibited a significantly increased EQE $>75 \%$ in the range of $450-800$ $\mathrm{nm}$. It is worth noting that $15.2 \%$ is the highest PCE for the ascast nonhalogenated processed OSC devices and the record PCE for OSCs based on high-permittivity $\left(\varepsilon_{\mathrm{r}}>5\right)$ organic semiconductors (Figure 3c,d, Tables S3 and S4).

\section{Exciton Dissociation and Charge Separation}

The exciton dissociation probability $P(E, T)$ was studied by the determination of the photocurrent density $\left(J_{\mathrm{ph}}\right)$ as a function of the effective voltage $\left(V_{\text {eff }}\right)$ (Figure $\left.S 5\right) .{ }^{47} P(E, T)$ is equal to $J_{\text {ph }} / J_{\text {sat }}$, where $J_{\text {sat }}$ is the saturated photocurrent density. When $V_{\text {eff }}$ was higher than $2 \mathrm{~V}$, the $J_{\text {ph }}$ values became saturated and were estimated to be $27.5 \mathrm{~mA} \mathrm{~cm}^{-2}$ for devices based on PM6:Y6-4O and $17.1 \mathrm{~mA} \mathrm{~cm}{ }^{-2}$ for devices based on PM6:Y6. Under short-circuit conditions, the $P(E, T)$ value of the devices based on PM6:Y6-4O was 0.96, which was much higher than that of PM6:Y6-based devices (0.90). This result implies that the exciton dissociation efficiency is better for the PM6:Y6-4O system and agrees well with the higher $\varepsilon_{\mathrm{r}}$ value of Y6-4O.
The exciton dissociation kinetics is closely related to the driving force $\left(\Delta E_{\mathrm{CT}}\right)$, which is defined as the difference between the band gap of the blend film $\left(E_{\mathrm{g}}{ }^{\mathrm{PV}}\right)$ and the energy of the charge-transfer $(\mathrm{CT})$ state $\left(E_{\mathrm{CT}}\right){ }^{48}$ The $E_{\mathrm{g}}{ }^{\mathrm{PV}}$ values for PM6:Y6 and PM6:Y6-4O were 1.39 and $1.42 \mathrm{eV}$, respectively, which were extracted from the maximum of the absolute value of the first derivative of EQE spectra in the low-energy region (Figure $3 \mathrm{~b}){ }^{49}$ The $E_{\mathrm{CT}}$ was deduced by fitting to the lowenergy part of the Fourier-transform photocurrent spectroscopy EQE (FTPS-EQE) spectra. ${ }^{50,51}$ From Figure S6, the $E_{\mathrm{CT}}$ values for PM6:Y6 and PM6:Y6-4O can be obtained as 1.35 and $1.38 \mathrm{eV}$, respectively. Consequently, both devices showed small $\Delta E_{\mathrm{CT}}$ values of $0.04 \mathrm{eV}$, indicating the same driving force for charge transfer and separation in the devices.

The transient absorption (TA) spectroscopy was carried out to further investigate the charge separation yield in the PM6:Y6 and PM6:Y6-4O films. ${ }^{52,53}$ The experimental conditions are described in the Supporting Information. Despite the distinct dielectric constants, we found that Y6 and $\mathrm{Y} 6-4 \mathrm{O}$ films showed identical exciton recombination dynamics, which were represented by the ground-state bleach (GSB) recovery kinetics (Figure S7). This observation implies that the introduction of an asymmetric OEG polarized side chain has a negligible impact on the exciton lifetime. Given the well-separated absorption peaks between acceptors and donors, we can tune the pump wavelength to selectively excite the acceptors (i.e., Y6 and Y6-4O) and avoid the excitation of PM6 in the blend films (Figure S4). As shown in Figure 4a,b, a negative peak centered at $830 \mathrm{~nm}$ appeared immediately after the optical excitation, corresponding to the $S_{1}$ exciton bleach of Y6/Y6-4O. The positive peaks at the lower energy side of the exciton bleach are then primarily attributed to the excited-state absorption (ESA). ${ }^{54}$ Meanwhile, other bleach signals were also 


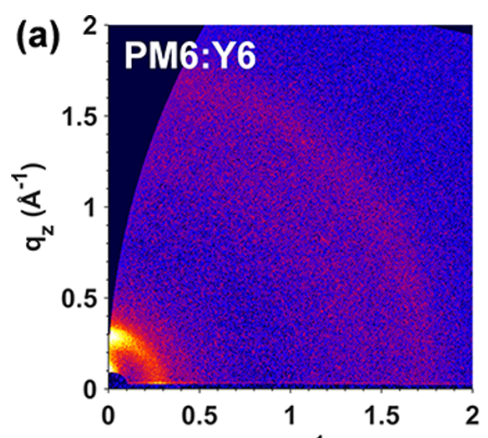

(c)

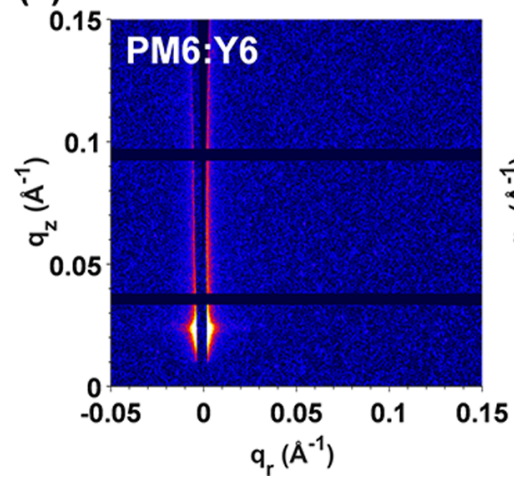

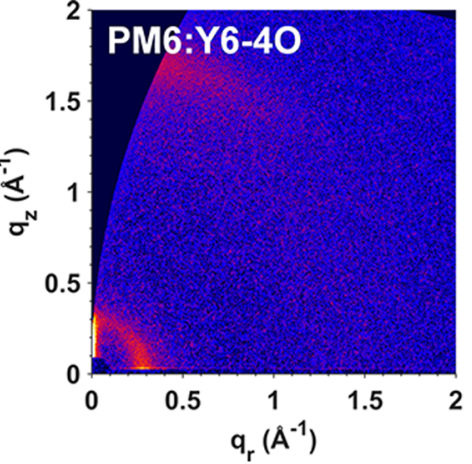

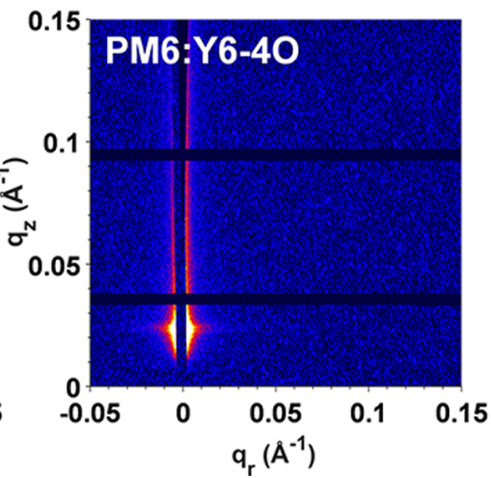

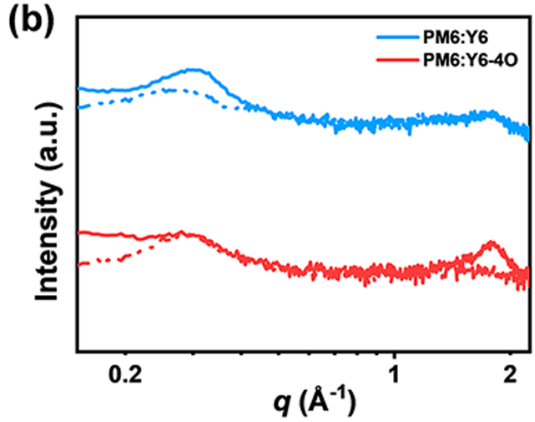

(d)

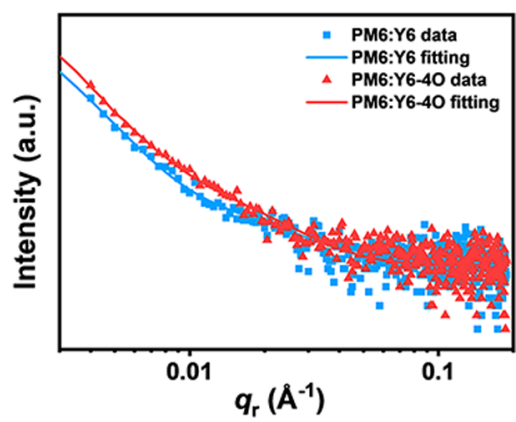

Figure 5. (a) 2D GIWAXS patterns, (b) GIWAXS intensity profiles along the in-plane (scattered line) and out-of-plane (solid line) directions, (c) 2D GISAXS patterns and (d) GISAXS intensity profiles and best fittings along the in-plane direction for PM6:Y6 and PM6:Y6-4O blend films.

formed at 580-630 $\mathrm{nm}$, which match the absorption peaks of PM6. This rapidly formed PM6 GSB has been attributed to the ultrafast direct exciton dissociation via the hole transfer at the interfaces between the acceptor and donor domains, leading to the spatially separated charges. ${ }^{54-56}$ As the delay increased, the exciton bleach of the acceptors gradually decreased, accompanied by the growth of the PM6 GSB. It is worth noting that the nearly unchanged GSB signal at the first vibronic position in PM6:Y6 is probably due to the spectral overlap between the PM6 and $\mathrm{Y} 6$ absorption peaks in the corresponding blend, and at such a position, the growth of PM6 bleach is coincidentally canceled out by the decay of Y6 bleach. This relatively slower spectral evolution has been attributed to the interfacial dissociation of the excitons that migrate from the inside of the acceptor domains to the interfaces, which reflects the exciton diffusion in the acceptor domains. ${ }^{55}$ In addition, the hole transfer from the acceptors to the donor also accounts for the ESA feature evolving into a broader positive feature, which has been ascribed to the spatially separated electrons and holes located in the acceptor and donor, respectively. ${ }^{54,57-59}$ Taking into account the electron-phonon interaction, these charge carriers can be treated as polarons. The Coulomb attraction can bind the oppositely signed polarons residing across the acceptor-donor interface as polaron pairs, which are then denoted as interfacial polaron pairs (i-PPs). On the basis of the previously described analysis, the amplitudes of the PM6 GSB and i-PP feature can be exploited to probe the charge separation (CS) yield in PM6:Y6 and PM6:Y6-4O. At a delay of $\sim 0.2 \mathrm{ps}$, the direct interfacial hole transfer is completed, but negligible excitons created inside the acceptor domains diffuse to the interfaces. The bleach amplitude of the acceptors at this delay indicates the number of excitons, and we can assume that there is the same number of the excitons in the two samples by scaling their TA spectra together (Figure 4c). At a delay of $\sim 80$ ps, both the PM6 GSB and the i-PP feature reached maxima, which is indicative of the fact that the diffusionlimited hole transfer was completed. We found that the TA spectra of the two samples at 80 ps with the same scaling factor used in the Figure 4d showed distinct PM6 GSB amplitudes. The PM6 GSB for the PM6:Y6-4O is twice that for the PM6:Y6, suggesting the much higher CS yield in the former.

The CS yield can also be evaluated from the dynamic perspective. The direct interfacial hole transfer takes place on a subpicosecond time scale, ${ }^{55}$ which is much shorter than the exciton lifetime in the acceptors. Thus the interfacial hole transfer should not limit the CS yield. On the contrary, the formed i-PPs can recombine across the boundary and relax to the ground state, which reduces the CS yield. Recently, studies have justified that the i-PPs can also relax to the triplet state of the acceptors, which has a detrimental impact on the device performance. $^{53,57}$ The interfacial recombination can be suppressed if the i-PPs dissociate into further separated electron and hole polarons. For those excitons inside the domains, they also undergo bulk recombination during the diffusion process. Thus the CS yield is not only determined by the diffusion but also depends on the interfacial i-PP recombination and dissociation. As shown in Figure 4e, both the formation and decay of the PM6 GSB kinetics in PM6:Y6 were slightly faster than those in PM6:Y6-4O. The neat film measurement justifies that the exciton recombinations in both Y6 and Y6-4O domains are similar. Thus the faster formation of PM6 GSB in Y6-based OSCs is likely due to the shorter diffusion distance, which is confirmed by the later measurement of grazingincidence small-angle X-ray scattering (GISAXS). If only the diffusion process is considered, then the CS yield in PM6:Y6 should be slightly higher than that in PM6:Y6-4O, which seems to contradict the conclusion based on the spectral results. The interfacial i-PP dynamics should also be taken into 
account. The exciton bleach recovery kinetics of acceptors in the two blend films are displayed in Figure 4f. At short delays, the exciton bleach of $\mathrm{Y} 6$ decayed significantly faster than that of Y6-4O, suggesting that compared with PM6:Y6-4O, more excited acceptors in PM6:Y6 return to the ground state via either exciton recombination or interfacial i-PP recombination. The former recombination channel depopulates the excited acceptors in the same rate, so this mechanism is ruled out. Thus the ultrafast i-PP recombination must account for the faster Y6 exciton bleach recovery. Therefore, we can now conclude that compared with PM6:Y6-4O, the lower CS yield in the PM6:Y6 is mainly due to the ultrafast interfacial i-PP recombination. Because a higher dielectric constant may cause smaller i-PP binding energy, which facilitates the i-PP dissociation and reduces the i-PP recombination probability, the higher dielectric constant of $\mathrm{Y} 6-4 \mathrm{O}$ might be responsible for the higher CS yield in the PM6:Y6-4O. ${ }^{41}$

The surface morphology of PM6:Y6 and PM6:Y6-4O blend films was investigated by atomic force microscopy (AFM) (Figure S8). The PM6:Y6-4O blend film shows an obviously smaller root-mean-square roughness of $1.46 \mathrm{~nm}$ than that of the PM6:Y6 film $(6.80 \mathrm{~nm})$. A smoother surface is beneficial for the formation of better interfacial contact. Grazingincidence wide-angle X-ray scattering (GIWAXS) and GISAXS were used to explore the molecular packing and nanoscale phase separation of blend films, respectively. ${ }^{60}$ The $2 \mathrm{D}$ GIWAXS patterns of neat and blend films and the corresponding out-of-plane (OOP)/in-plane (IP) linecut profiles are exhibited in Figure S9 and Figure 5, respectively. The PM6:Y6 blend film shows a strong OOP lamellar peak at $q_{z}=0.302 \AA^{-1}(d=20.8 \AA)$ and a relatively weaker IP lamellar peak at $q_{\mathrm{r}}=0.276 \AA^{-1}(d=22.8 \AA)$, which originated from the edge-on oriented PM6 and the face-on oriented Y 6 crystalline domains, respectively. On the contrary, the film of PM6:Y6-4O shows a preferential face-on orientation with a strong IP lamellar peak at $q_{\mathrm{r}}=0.284 \AA^{-1}(d=22.1 \AA)$ and a well-defined OOP $\pi-\pi$ stacking peak at $q_{z}=1.81 \AA^{-1}(d=3.47 \AA)$, and both peaks can be traced back to face-on oriented Y6-4O. In addition, 2D GISAXS patterns, the corresponding fitted intensity profiles in the IP direction, and the domain size data are shown in Figure 5 and Table S5. The acceptor domain sizes $\left(2 R_{\mathrm{g}}\right)$ of PM6:Y6 and PM6:Y6-4O blends are fitted to be 15.8 and $20.8 \mathrm{~nm}$, respectively, which may explain the faster formation of PM6 GSB in PM6:Y6 blend films relative to Y64O-based films.

\section{Charge Recombination and Voltage Loss}

The bimolecular recombination coefficient $(\beta)$ can be defined by the following expression ${ }^{61,62}$

$$
\beta=\gamma k_{\mathrm{L}}=\left[\frac{16 \pi}{9} \frac{\mu_{\mathrm{e}} \mu_{\mathrm{h}}}{\mu_{\text {double }}^{2}-\left(\mu_{\mathrm{e}}+\mu_{\mathrm{h}}\right)^{2}}\right]\left[\frac{q\left(\mu_{\mathrm{e}}+\mu_{\mathrm{h}}\right)}{\varepsilon_{0} \varepsilon_{\mathrm{r}}}\right]
$$

where $\gamma$ is a dimensionless parameter, $k_{\mathrm{L}}$ is the Langevin rate constant, $\mu_{\text {double }}$ is the effective mobility of the double carrier device, $\mu_{\mathrm{h}}$ and $\mu_{\mathrm{e}}$ are the hole and electron mobility in the blend films, and $\varepsilon_{\mathrm{r}}$ is the average value for the donor and acceptor (Figure S10). According to the results of the SCLC method (Figures S11 and S12), the PM6:Y6 blend film showed a $\mu_{\mathrm{h}}$ of $8.4 \times 10^{-5} \mathrm{~cm}^{2} \mathrm{~V}^{-1} \mathrm{~s}^{-1}$, a $\mu_{\mathrm{e}}$ of $0.74 \times 10^{-5} \mathrm{~cm}^{2}$ $\mathrm{V}^{-1} \mathrm{~s}^{-1}$, and a $\gamma$ of 0.15 . In contrast, the PM6:Y6-4O blend film exhibited more balanced mobilities $\left(\mu_{\mathrm{h}}=3.2 \times 10^{-5} \mathrm{~cm}^{2} \mathrm{~V}^{-1}\right.$ $\left.\mathrm{s}^{-1} ; \mu_{\mathrm{e}}=2.7 \times 10^{-5} \mathrm{~cm}^{2} \mathrm{~V}^{-1} \mathrm{~s}^{-1}\right)$ and a much smaller $\gamma$ of
0.017 . As a result, $\beta$ can be calculated as $7.2 \times 10^{-18} \mathrm{~m}^{3} \mathrm{~s}^{-1}$ for PM6:Y6 and $4.4 \times 10^{-19} \mathrm{~m}^{3} \mathrm{~s}^{-1}$ for PM6:Y6-4O, respectively. Because of the higher $\varepsilon_{\mathrm{r}}$ and the more balanced charge-carrier transport, PM6:Y6-4O exhibited a smaller bimolecular recombination coefficient, which can notably reduce the charge recombination and further lead to a higher $J_{\mathrm{SC}}$. According to the previous work, the decreased bimolecular recombination loss related to a larger dielectric constant can play an important role in lowering the open-circuit voltage loss $\left(V_{\text {loss }}\right)$ of OSC devices, which is defined as the difference between the $E_{\mathrm{g}}^{\mathrm{PV}} / q$ and the $V_{\mathrm{OC}}{ }^{63,64} \mathrm{PM} 6: Y 6-4 \mathrm{O}-$ based devices exhibited a smaller $V_{\text {loss }}$ of $0.57 \mathrm{~V}$ relative to PM6:Y6based devices $\left(V_{\text {loss }}=0.59 \mathrm{~V}\right)$. The larger dielectric constant of Y6-4O leads to a smaller $V_{\text {loss }}$ of PM6:Y6-4O based devices, which is beneficial for the higher $V_{\mathrm{OC}}$ and PCE.

\section{CONCLUSIONS}

In summary, we used a rational molecular design strategy to simultaneously enhance the permittivity and ecocompatibility of the high-performance electron acceptor Y6 through introducing an asymmetric highly polarizable OEG chain onto the pyrrole unit. Compared with Y6 $\left(\varepsilon_{\mathrm{r}}=3.36\right)$, Y6-4O with a larger dipole moment had a higher dielectric constant of 5.13 and excellent solubility in nonhalogen solvents. The higher $\varepsilon_{\mathrm{r}}$ value had a negligible impact on the optical property, energy levels, and exciton lifetime of $\mathrm{Y} 6-4 \mathrm{O}$ but led to more efficient exciton dissociation, slower bimolecular recombination kinetics, and less voltage loss of the toluene-processed devices based on as-cast PM6:Y6-4O. Consequently, a high PCE of $15.2 \%$ was achieved for PM6:Y6-4O based devices, much higher than that of the control devices based on PM6:Y6 $(7.38 \%)$. It is worth noting that $15.2 \%$ is the highest PCE for the as-cast nonhalogenated processed OSC devices and the record PCE for OSCs based on high-permittivity $\left(\varepsilon_{\mathrm{r}}>5\right)$ organic semiconductors. These results imply that the strategy of asymmetric substitution with an OEG side chain can simultaneously enhance the dielectric constant and the solubility of organic semiconductors, which is very promising for achieving high performance in ecofriendly solventprocessed OSC devices.

\section{ASSOCIATED CONTENT}

\section{Supporting Information}

The Supporting Information is available free of charge at https://pubs.acs.org/doi/10.1021/jacsau.1c00306.

Detailed experimental procedures including materials, synthesis, characterization, device fabrication and characterization, femtosecond transient absorption, and mobility measurements, additional characterization data, Scheme S1, Figure S1-S12, and Table S1-S5 (PDF)

\section{AUTHOR INFORMATION}

\section{Corresponding Authors}

Yuze Lin - Beijing National Laboratory for Molecular Sciences, CAS Key Laboratory of Organic Solids, Institute of Chemistry, Chinese Academy of Sciences, Beijing 100190, China; University of Chinese Academy of Sciences, Beijing 100049, China; 이이이.org/0000-0002-0325-3842; Email: linyz@iccas.ac.cn

Ye Yang - State Key Laboratory of Physical Chemistry of Solid Surfaces, College of Chemistry and Chemical Engineering, 
Xiamen University, Xiamen 361005, China; 이이.org/ 0000-0003-2827-3572; Email: ye.yang@xmu.edu.cn

\section{Authors}

Tengfei Li - Beijing National Laboratory for Molecular Sciences, CAS Key Laboratory of Organic Solids, Institute of Chemistry, Chinese Academy of Sciences, Beijing 100190, China

Kang Wang - State Key Laboratory of Physical Chemistry of Solid Surfaces, College of Chemistry and Chemical Engineering, Xiamen University, Xiamen 361005, China

Guilong Cai - Department of Physics, The Chinese University of Hong Kong, 999077 Hong Kong, China; 이이.org/ 0000-0001-9924-1362

Yawen Li - Beijing National Laboratory for Molecular Sciences, CAS Key Laboratory of Organic Solids, Institute of Chemistry, Chinese Academy of Sciences, Beijing 100190, China

Heng Liu - Department of Physics, The Chinese University of Hong Kong, 999077 Hong Kong, China

Yixiao Jia - Beijing National Laboratory for Molecular Sciences, CAS Key Laboratory of Organic Solids, Institute of Chemistry, Chinese Academy of Sciences, Beijing 100190, China

Zhenzhen Zhang - Beijing National Laboratory for Molecular Sciences, CAS Key Laboratory of Organic Solids, Institute of Chemistry, Chinese Academy of Sciences, Beijing 100190, China; University of Chinese Academy of Sciences, Beijing 100049, China

Xinhui Lu - Department of Physics, The Chinese University of Hong Kong, 999077 Hong Kong, China

Complete contact information is available at:

https://pubs.acs.org/10.1021/jacsau.1c00306

\section{Notes}

The authors declare no competing financial interest.

\section{ACKNOWLEDGMENTS}

We thank the Chinese Academy of Sciences for financial support.

\section{REFERENCES}

(1) Yu, G.; Gao, J.; Hummelen, J. C.; Wudl, F.; Heeger, A. J. Polymer photovoltaic cells - enhanced efficiencies via a network of internal donor-acceptor heterojunctions. Science 1995, 270, 17891791.

(2) Lu, L.; Zheng, T.; Wu, Q.; Schneider, A. M.; Zhao, D.; Yu, L. Recent advances in bulk heterojunction polymer solar cells. Chem. Rev. 2015, 115, 12666-12731.

(3) Li, T.; Zhan, X. Advances in organic photovoltaics. Huaxue Xuebao 2021, 79, 257.

(4) Cheng, P.; Yang, Y. Narrowing the band gap: The key to highperformance organic photovoltaics. Acc. Chem. Res. 2020, 53, 12181228.

(5) Yan, C.; Barlow, S.; Wang, Z.; Yan, H.; Jen, A. K.-Y.; Marder, S. R.; Zhan, X. Non-fullerene acceptors for organic solar cells. Nat. Rev. Mater. 2018, 3, 18003.

(6) Zhang, G.; Zhao, J.; Chow, P. C. Y.; Jiang, K.; Zhang, J.; Zhu, Z.; Zhang, J.; Huang, F.; Yan, H. Nonfullerene acceptor molecules for bulk heterojunction organic solar cells. Chem. Rev. 2018, 118, 34473507.

(7) Lin, Y.; Wang, J.; Zhang, Z. G.; Bai, H.; Li, Y.; Zhu, D.; Zhan, X. An electron acceptor challenging fullerenes for efficient polymer solar cells. Adv. Mater. 2015, 27, 1170-1174.
(8) Zhao, W.; Li, S.; Yao, H.; Zhang, S.; Zhang, Y.; Yang, B.; Hou, J. Molecular optimization enables over $13 \%$ efficiency in organic solar cells. J. Am. Chem. Soc. 2017, 139, 7148-7151.

(9) Li, T.; Dai, S.; Ke, Z.; Yang, L.; Wang, J.; Yan, C.; Ma, W.; Zhan, $\mathrm{X}$. Fused tris(thienothiophene)-based electron acceptor with strong near-infrared absorption for high-performance as-cast solar cells. Adv. Mater. 2018, 30, 1705969.

(10) Li, X.; Pan, F.; Sun, C.; Zhang, M.; Wang, Z.; Du, J.; Wang, J.; Xiao, M.; Xue, L.; Zhang, Z. G.; Zhang, C.; Liu, F.; Li, Y. Simplified synthetic routes for low cost and high photovoltaic performance ntype organic semiconductor acceptors. Nat. Commun. 2019, 10, 519.

(11) Jiang, K.; Wei, Q.; Lai, J. Y. L.; Peng, Z.; Kim, H. K.; Yuan, J.; Ye, L.; Ade, H.; Zou, Y.; Yan, H. Alkyl chain tuning of small molecule acceptors for efficient organic solar cells. Joule 2019, 3, 3020-3033.

(12) Meng, L.; Zhang, Y.; Wan, X.; Li, C.; Zhang, X.; Wang, Y.; Ke, X.; Xiao, Z.; Ding, L.; Xia, R.; Yip, H.-L.; Cao, Y.; Chen, Y. Organic and solution-processed tandem solar cells with $17.3 \%$ efficiency. Science 2018, 361, 1094-1098.

(13) Yuan, J.; Zhang, Y.; Zhou, L.; Zhang, G.; Yip, H.-L.; Lau, T.-K.; Lu, X.; Zhu, C.; Peng, H.; Johnson, P. A.; Leclerc, M.; Cao, Y.; Ulanski, J.; Li, Y.; Zou, Y. Single-junction organic solar cell with over $15 \%$ efficiency using fused-ring acceptor with electron-deficient core. Joule 2019, 3, 1140-1151.

(14) Liu, S.; Yuan, J.; Deng, W.; Luo, M.; Xie, Y.; Liang, Q.; Zou, Y.; He, Z.; Wu, H.; Cao, Y. High-efficiency organic solar cells with low non-radiative recombination loss and low energetic disorder. Nat. Photonics 2020, 14, 300-305.

(15) Li, Y.; Zhang, Z.; Han, X.; Li, T.; Lin, Y. Fine-tuning contact via complexation for high-performance organic solar cells. CCS Chem. 2021, 3, 1206-1216.

(16) Zhang, Y.; Cai, G.; Li, Y.; Zhang, Z.; Li, T.; Zuo, X.; Lu, X.; Lin, $\mathrm{Y}$. An electron acceptor analogue for lowering trap density in organic solar cells. Adv. Mater. 2021, 33, 2008134.

(17) Ma, Y.; Zhang, M.; Wan, S.; Yin, P.; Wang, P.; Cai, D.; Liu, F.; Zheng, Q. Efficient organic solar cells from molecular orientation control of m-series acceptors. Joule 2021, 5, 197-209.

(18) Nian, L.; Kan, Y. Y.; Gao, K.; Zhang, M.; Li, N.; Zhou, G. Q.; Jo, S. B.; Shi, X. L.; Lin, F.; Rong, Q. K.; Liu, F.; Zhou, G. F.; Jen, A. K. Y. Approaching $16 \%$ efficiency in all-small-molecule organic solar cells based on ternary strategy with a highly crystalline acceptor. Joule 2020, 4, 2223-2236.

(19) Zhang, Z.; Li, Y.; Cai, G.; Zhang, Y.; Lu, X.; Lin, Y. Selenium heterocyclic electron acceptor with small urbach energy for as-cast high-performance organic solar cells. J. Am. Chem. Soc. 2020, 142, 18741-18745.

(20) Liu, Q.; Jiang, Y.; Jin, K.; Qin, J.; Xu, J.; Li, W.; Xiong, J.; Liu, J.; Xiao, Z.; Sun, K.; Yang, S.; Zhang, X.; Ding, L. 18\% efficiency organic solar cells. Sci. Bull. 2020, 65, 272-275.

(21) Green, M. A.; Dunlop, E. D.; Hohl-Ebinger, J.; Yoshita, M.; Kopidakis, N.; Ho-Baillie, A. W. Y. Solar cell efficiency tables (version 55). Prog. Photovoltaics 2020, 28, 3-15.

(22) Koster, L. J. A.; Shaheen, S. E.; Hummelen, J. C. Pathways to a new efficiency regime for organic solar cells. Adv. Energy Mater. 2012, 2, 1246-1253.

(23) Samiee, M.; Konduri, S.; Ganapathy, B.; Kottokkaran, R.; Abbas, H. A.; Kitahara, A.; Joshi, P.; Zhang, L.; Noack, M.; Dalal, V. Defect density and dielectric constant in perovskite solar cells. Appl. Phys. Lett. 2014, 105, 153502.

(24) Gregg, B. A.; Hanna, M. C. Comparing organic to inorganic photovoltaic cells: Theory, experiment, and simulation. J. Appl. Phys. 2003, 93, 3605-3614.

(25) Gledhill, S. E.; Scott, B.; Gregg, B. A. Organic and nanostructured composite photovoltaics: An overview. J. Mater. Res. 2005, $20,3167-3179$.

(26) Liu, X.; Xie, B. M.; Duan, C. H.; Wang, Z. J.; Fan, B. B.; Zhang, K.; Lin, B. J.; Colberts, F. J. M.; Ma, W.; Janssen, R. A. J.; Huang, F.; Cao, Y. A high dielectric constant non-fullerene acceptor for efficient bulk-heterojunction organic solar cells. J. Mater. Chem. A 2018, 6, 395-403. 
(27) Brebels, J.; Manca, J. V.; Lutsen, L.; Vanderzande, D.; Maes, W. High dielectric constant conjugated materials for organic photovoltaics. J. Mater. Chem. A 2017, 5, 24037-24050.

(28) Cho, N.; Schlenker, C. W.; Knesting, K. M.; Koelsch, P.; Yip, H. L.; Ginger, D. S.; Jen, A. K. Y. High-dielectric constant side-chain polymers show reduced non-geminate recombination in heterojunction solar cells. Adv. Energy Mater. 2014, 4, 1301857.

(29) Jahani, F.; Torabi, S.; Chiechi, R. C.; Koster, L. J. A.; Hummelen, J. C. Fullerene derivatives with increased dielectric constants. Chem. Commun. 2014, 50, 10645-10647.

(30) Zhang, S.; Zhang, Z. J.; Liu, J.; Wang, L. X. Fullerene adducts bearing cyano moiety for both high dielectric constant and good active layer morphology of organic photovoltaics. Adv. Funct. Mater. 2016, 26, 6107-6113.

(31) Chen, X.; Zhang, Z.; Ding, Z.; Liu, J.; Wang, L. Diketopyrrolopyrrole-based conjugated polymers bearing branched oligo(ethylene glycol) side chains for photovoltaic devices. Angew. Chem., Int. Ed. 2016, 55, 10376-10380.

(32) Armin, A.; Stoltzfus, D. M.; Donaghey, J. E.; Clulow, A. J.; Nagiri, R. C. R.; Burn, P. L.; Gentle, I. R.; Meredith, P. Engineering dielectric constants in organic semiconductors. J. Mater. Chem. C 2017, 5, 3736-3747.

(33) Jang, B.; Lee, C.; Lee, Y. W.; Kim, D.; Uddin, M. A.; Kim, F. S.; Kim, B. J.; Woo, H. Y. A high dielectric n-type small molecular acceptor containing oligoethyleneglycol side-chains for organic solar cells. Chin. J. Chem. 2018, 36, 199-205.

(34) Zhang, S.; Ye, L.; Zhang, H.; Hou, J. Green-solvent-processable organic solar cells. Mater. Today 2016, 19, 533-543.

(35) Volksen, W.; Miller, R. D.; Dubois, G. Low dielectric constant materials. Chem. Rev. 2010, 110, 56-110.

(36) Zhang, X.; Zhang, D.; Zhou, Q.; Wang, R.; Zhou, J.; Wang, J.; Zhou, H.; Zhang, Y. Fluorination with an enlarged dielectric constant prompts charge separation and reduces bimolecular recombination in non-fullerene organic solar cells with a high fill factor and efficiency $>$ 13\%. Nano Energy 2019, 56, 494-501.

(37) Wudarczyk, J.; Papamokos, G.; Margaritis, V.; Schollmeyer, D.; Hinkel, F.; Baumgarten, M.; Floudas, G.; Mullen, K. Hexasubstituted benzenes with ultrastrong dipole moments. Angew. Chem., Int. Ed. 2016, 55, 3220-3223.

(38) Lin, Y.; He, Q.; Zhao, F.; Huo, L.; Mai, J.; Lu, X.; Su, C. J.; Li, T.; Wang, J.; Zhu, J.; Sun, Y.; Wang, C.; Zhan, X. A facile planar fused-ring electron acceptor for as-cast polymer solar cells with $8.71 \%$ efficiency. J. Am. Chem. Soc. 2016, 138, 2973-2976.

(39) Dai, S.; Zhao, F.; Zhang, Q.; Lau, T. K.; Li, T.; Liu, K.; Ling, Q.; Wang, C.; Lu, X.; You, W.; Zhan, X. Fused nonacyclic electron acceptors for efficient polymer solar cells. J. Am. Chem. Soc. 2017, 139, $1336-1343$.

(40) Torabi, S.; Jahani, F.; Van Severen, I.; Kanimozhi, C.; Patil, S.; Havenith, R. W. A.; Chiechi, R. C.; Lutsen, L.; Vanderzande, D. J. M.; Cleij, T. J.; Hummelen, J. C.; Koster, L. J. A. Strategy for enhancing the dielectric constant of organic semiconductors without sacrificing charge carrier mobility and solubility. Adv. Funct. Mater. 2015, 25, $150-157$.

(41) Clarke, T. M.; Durrant, J. R. Charge photogeneration in organic solar cells. Chem. Rev. 2010, 110, 6736-6767.

(42) Bredas, J.-L. Mind the gap! Mater. Horiz. 2014, 1, 17-19.

(43) Yao, J.; Qiu, B.; Zhang, Z. G.; Xue, L.; Wang, R.; Zhang, C.; Chen, S.; Zhou, Q.; Sun, C.; Yang, C.; Xiao, M.; Meng, L.; Li, Y. Cathode engineering with perylene-diimide interlayer enabling over $17 \%$ efficiency single-junction organic solar cells. Nat. Commun. 2020, 11, 2726.

(44) Leblebici, S. Y.; Chen, T. L.; Olalde-Velasco, P.; Yang, W.; Ma, B. Reducing exciton binding energy by increasing thin film permittivity: An effective approach to enhance exciton separation efficiency in organic solar cells. ACS Appl. Mater. Interfaces 2013, 5, 10105-10110.

(45) Malliaras, G. G.; Salem, J. R.; Brock, P. J.; Scott, C. Electrical characteristics and efficiency of single-layer organic light-emitting diodes. Phys. Rev. B: Condens. Matter Mater. Phys. 1998, 58, R13411.
(46) Zhang, M.; Guo, X.; Ma, W.; Ade, H.; Hou, J. A large-bandgap conjugated polymer for versatile photovoltaic applications with high performance. Adv. Mater. 2015, 27, 4655-4660.

(47) Lu, L.; Xu, T.; Chen, W.; Landry, E. S.; Yu, L. Ternary blend polymer solar cells with enhanced power conversion efficiency. Nat. Photonics 2014, 8, 716-722.

(48) Chen, S.; Wang, Y.; Zhang, L.; Zhao, J.; Chen, Y.; Zhu, D.; Yao, H.; Zhang, G.; Ma, W.; Friend, R. H.; Chow, P. C. Y.; Gao, F.; Yan, $\mathrm{H}$. Efficient nonfullerene organic solar cells with small driving forces for both hole and electron transfer. Adv. Mater. 2018, 30, 1804215.

(49) Rau, U.; Blank, B.; Muller, T. C. M.; Kirchartz, T. Efficiency potential of photovoltaic materials and devices unveiled by detailedbalance analysis. Phys. Rev. Appl. 2017, 7, No. 044016.

(50) Karki, A.; Vollbrecht, J.; Dixon, A. L.; Schopp, N.; Schrock, M.; Reddy, G. N. M.; Nguyen, T. Q. Understanding the high performance of over $15 \%$ efficiency in single-junction bulk heterojunction organic solar cells. Adv. Mater. 2019, 31, 1903868.

(51) Wang, Y.; Jia, B.; Wang, J.; Xue, P.; Xiao, Y.; Li, T.; Wang, J.; Lu, H.; Tang, Z.; Lu, X.; Huang, F.; Zhan, X. High-efficiency perovskite quantum dot hybrid nonfullerene organic solar cells with near-zero driving force. Adv. Mater. 2020, 32, 2002066.

(52) Bakulin, A. A.; Rao, A.; Pavelyev, V. G.; van Loosdrecht, P. H. M.; Pshenichnikov, M. S.; Niedzialek, D.; Cornil, J.; Beljonne, D.; Friend, R. H. The role of driving energy and delocalized states for charge separation in organic semiconductors. Science 2012, 335, $1340-1344$.

(53) Wang, R.; Xu, J.; Fu, L.; Zhang, C.; Li, Q.; Yao, J.; Li, X.; Sun, C.; Zhang, Z. G.; Wang, X.; Li, Y.; Ma, J.; Xiao, M. Nonradiative triplet loss suppressed in organic photovoltaic blends with fluoridated nonfullerene acceptors. J. Am. Chem. Soc. 2021, 143, 4359-4366.

(54) Wang, R.; Zhang, C.; Li, Q.; Zhang, Z.; Wang, X.; Xiao, M. Charge separation from an intra-moiety intermediate state in the highperformance pm6:Y6 organic photovoltaic blend. J. Am. Chem. Soc. 2020, 142, 12751-12759.

(55) Chen, Z.; Chen, X.; Qiu, B.; Zhou, G.; Jia, Z.; Tao, W.; Li, Y.; Yang, Y. M.; Zhu, H. Ultrafast hole transfer and carrier transport controlled by nanoscale-phase morphology in nonfullerene organic solar cells. J. Phys. Chem. Lett. 2020, 11, 3226-3233.

(56) Niu, M.-S.; Wang, K.-W.; Yang, X.-Y.; Bi, P.-Q.; Zhang, K.-N.; Feng, X.-J.; Chen, F.; Qin, W.; Xia, J.-L.; Hao, X.-T. Hole transfer originating from weakly bound exciton dissociation in acceptordonor-acceptor nonfullerene organic solar cells. J. Phys. Chem. Lett. 2019, 10, 7100-7106.

(57) Chen, Z.; Chen, X.; Jia, Z. Y.; Zhou, G. Q.; Xu, J. Q.; Wu, Y. X.; Xia, X. X.; Li, X. F.; Zhang, X. N.; Deng, C.; Zhang, Y.; Lu, X. H.; Liu, W. M.; Zhang, C. F.; Yang, Y.; Zhu, H. M. Triplet exciton formation for non-radiative voltage loss in high-efficiency nonfullerene organic solar cells. Joule 2021, 5, 1832-1844.

(58) Wang, K.; Chen, H.; Zhang, J.; Zou, Y.; Yang, Y. Intrachain and interchain exciton-exciton annihilation in donor-acceptor copolymers. J. Phys. Chem. Lett. 2021, 12, 3928-3933.

(59) Zhou, G.; Ding, H.; Zhu, L.; Qiu, C.; Zhang, M.; Hao, T.; Feng, W.; Zhang, Y.; Zhu, H.; Liu, F. Photophysics, morphology and device performances correlation on non-fullerene acceptor based binary and ternary solar cells. J. Energy Chem. 2020, 47, 180-187.

(60) Mai, J.; Lau, T.-K.; Li, J.; Peng, S.-H.; Hsu, C.-S.; Jeng, U. S.; Zeng, J.; Zhao, N.; Xiao, X.; Lu, X. Understanding morphology compatibility for high-performance ternary organic solar cells. Chem. Mater. 2016, 28, 6186-6195.

(61) Langevin, P. Recombinaison et mobilites des ions dans les gaz. Ann. Chim. Phys. 1903, 28 (7), 433.

(62) Wetzelaer, G.-J. A. H.; Van der Kaap, N. J.; Koster, L. J. A.; Blom, P. W. M. Quantifying bimolecular recombination in organic solar cells in steady state. Adv. Energy Mater. 2013, 3, 1130-1134.

(63) Fu, Z.; Zhang, X.; Zhang, H.; Li, Y.; Zhou, H.; Zhang, Y. On the understandings of dielectric constant and its impacts on the photovoltaic efficiency in organic solar cells. Chin. J. Chem. 2021, 39, 381-390. 
(64) Collins, S. D.; Proctor, C. M.; Ran, N. A.; Nguyen, T.-Q. Understanding open-circuit voltage loss through the density of states in organic bulk heterojunction solar cells. Adv. Energy Mater. 2016, 6, 1501721. 